\title{
"Nurses and midwives: clean care is in your hands": the 5th May 2020 World Health Organization SAVE LIVES: Clean Your Hands campaign
}

\author{
Alexandra Peters ${ }^{1}$, Nasim Lotfinejad ${ }^{2}$, Chloé Guitart ${ }^{1}$, Alice Simniceanu ${ }^{3}$, Maria Clara Padoveze ${ }^{4}$, \\ Tcheun Borzykowski ${ }^{1}$, Benedetta Allegranzi ${ }^{4}$ and Didier Pittet ${ }^{1 *}$
}

\begin{abstract}
In honor of Florence Nightingale's 200th birthday, the World Health Organization (WHO) has declared 2020 the "Year of the Nurse and Midwife". On May 5th of this year, for the annual celebration of the SAVE LIVES: Clean Your Hands campaign, WHO will focus on the essential role that nurses and midwives play in contributing to saving millions of lives per year. It is necessary to recognize the work and the immense responsibility that nurses and midwives carry since achieving Universal Health Coverage is highly reliant on them.
\end{abstract}

Keywords: Infection prevention and control, Infection control, Hand hygiene, Nurses, Midwives, World Health Organization, Healthcare-associated infection

\section{Background}

In honor of Florence Nightingale's 200th birthday, the World Health Organization (WHO) has declared 2020 the "Year of the Nurse and Midwife". In addition to championing the nursing profession, Nightingale's role was also fundamental for the recognition of the importance of infection prevention and control (IPC), as she was among the first to recognize that a caregiver could transmit germs, and thus cause patient harm. Nurses and midwives make up nearly $50 \%$ of the global health workforce [1], and are the group of healthcare workers that have the most frequent contact with patients. This makes them pivotal figures in the fight against healthcareassociated infections (HAI) as well as neonatal and maternal sepsis.

\footnotetext{
* Correspondence: didier.pittet@hcuge.ch

'Infection Control Program, University of Geneva Hospitals and Faculty of Medicine, Geneva, Switzerland

Full list of author information is available at the end of the article
}

On the 5th May 2020, for the annual celebration of the SAVE LIVES: Clean Your Hands campaign, WHO will focus on the essential role that nurses and midwives play in contributing to saving millions of lives each year by championing clean care (Fig. 1). Despite many improvements around the world, rates of HAI remain unacceptably high, and the majority of them are transmitted by healthcare workers' hands. Therefore, hand hygiene promotion strategies must be constantly reinforced and improved. Clean healthcare has recently been recognized by WHO as one of the most urgent challenges to be tackled by the global community over the next ten year [2] Actively engaging the expertise of nurses and midwives in the development, implementation and evaluation of hand hygiene promotion contributes to clean healthcare.

Along with recognizing the critical importance of nurses and midwives to patient care, the aim of the "Year of the Nurse and Midwife" is also to highlight that there is a major global shortage of healthcare workers, and that more than half of the shortage is of nurses and 
Table 1 The 5 May 2020 World Health Organization SAVE LIVES: Clean Your Hands Campaign Calls to Action

\begin{tabular}{ll}
\hline $\begin{array}{l}\text { Campaign } \\
\text { Participants }\end{array}$ & Call to Action \\
\hline $\begin{array}{l}\text { Nurses } \\
\text { Midwives }\end{array}$ & "Clean and safe care starts with you." \\
"Your hands make all the difference for mothers and \\
babies."
\end{tabular}

Abbreviations: IPC infection prevention and control; WHO World Health Organization

midwives [1]. WHO estimates that for countries to succeed in reaching the Sustainable Development Goal \# 3 on health and well-being, the world will need an additional 9 million nurses and midwives by the year 2030 [1]. It has been proven that investing in education and job creation in the health and social sectors will result in improved health outcomes, global health security, and economic growth [1]. Having adequate healthcare worker staffing reduces the risk of HAI and antimicrobial resistance, and is thus recommended by WHO as a core component of effective IPC programmes [3].

It is crucial to recognize both the work and the immense responsibility that nurses and midwives carry: we cannot achieve Universal Health Coverage without investing in them. Everyone- including policy makers, healthcare workers, and patients themselves- can contribute to improving hand hygiene and preventing infections (Table 1).

Please join us in celebrating this vital and often underappreciated group of HCW; "Nurses and Midwives: CLEAN CARE is in YOUR HANDS"!

\section{Conclusion}

Nurses and midwives make are the group of healthcare workers that have the most frequent contact with patients, making them pivotal figures in the fight against healthcare- associated infections as well as neonatal and maternal sepsis. Despite many improvements around the world, rates of healthcare- associated infections remain

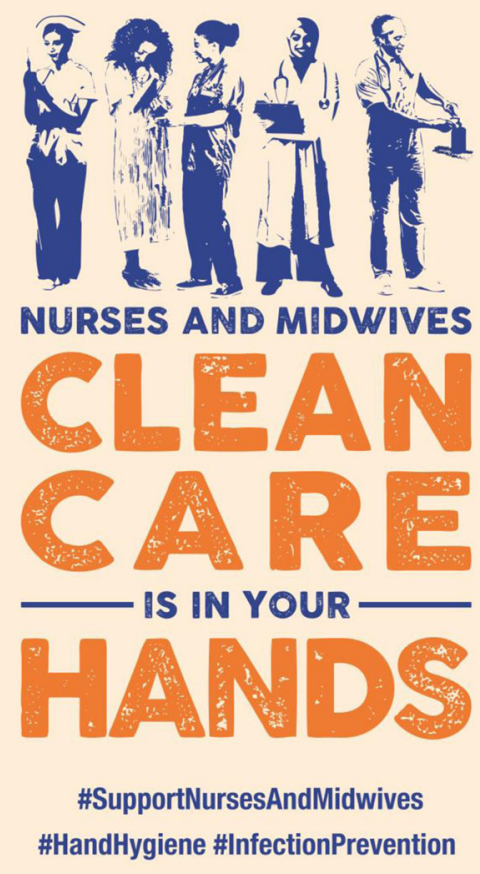

Fig. 1 May 5, 2020: "Nurses and Midwives, clean care is in your hands!". The May 5, 2020, World Health Organization SAVE LIVES: Clean Your Hands campaign slogan and main promotional image (2020 hashtags: \#SupportNursesAndMidwives \#HandHygiene \#InfectionPrevention). Campaign participants are invited to submit photos or selfies of them holding a board with the slogan and hashtags

at www.CleanHandsSaveLives.org 
unacceptably high, and the majority of them are transmitted by healthcare workers' hands. Please join us in celebrating this vital and often underappreciated group of healthcare workers. "Nurses and midwives: CLEAN CARE is in YOUR HANDS"!

\section{Acknowledgements}

Didier Pittet works with WHO in the context of the WHO initiative 'Private Organizations for Patient Safety - Hand Hygiene'. The aim of this WHO initiative is to harness industry strengths to align and improve implementation of WHO recommendations for hand hygiene in health care indifferent parts of the world, including in least developed countries. In this instance, companies/industry with a focus on hand hygiene and infection control related advancement have the specific aim of improving access to affordable hand hygiene products as well as through education and research. All listed authors declare no financial support, grants, financial interests or consultancy that could lead to conflicts of interest.

The authors alone are responsible for the views expressed in this article and they do not necessarily represent the views, decisions or policies of the institutions with which they are affiliated. WHO takes no responsibility for the information provided or the views expressed in this paper.

\section{Disclaimer}

The views expressed in this article are those of the authors alone and do not necessarily represent the views, decisions, or policies of the institutions with which the authors are affiliated. The World Health Organization (WHO) takes no responsibility for the information provided or the views expressed in this article.

\section{Authors' contributions}

All authors helped with drafting the manuscript. DP critically revised and supervised the study. All authors read and approved the final manuscript.

\section{Funding}

This work is supported by WHO, Geneva, Switzerland, and the Infection Control Program, University of Geneva Hospitals and Faculty of Medicine, Geneva, Switzerland; hand hygiene research activities at the SPCIMCC are also supported by the Swiss National Science Foundation (grant number 32003B_163262). Potential conflicts of interest.

\section{Availability of data and materials}

Data sharing not applicable to this article as no datasets were generated or analyzed during the current study.

\section{Ethics approval and consent to participate}

Not applicable.

\section{Consent for publication}

Not applicable.

\section{Competing interests}

The authors declare that they have no competing interests. All authors have submitted the ICMJE Form for Disclosure of Potential Conflicts of Interest. Conflicts that the editors consider relevant to the content of the manuscript have been disclosed.

\section{Author details}

${ }^{1}$ Infection Control Program, University of Geneva Hospitals and Faculty of Medicine, Geneva, Switzerland. ${ }^{2}$ Department of Research, Faculty of Medicine, Mashhad University of Medical Sciences, Mashhad, Iran. ${ }^{3}$ Infection Prevention and Control Hub and Antimicrobial Resistance Division, World Health Organization, Geneva, Switzerland. ${ }^{4}$ Infection Prevention and Control Hub, Integrated Health Services, UHC/Life Course, World Health Organization, Geneva, Switzerland.
Received: 26 March 2020 Accepted: 2 April 2020

Published online: 19 April 2020

\section{References}

1. Nursing and midwifery. Fact sheets: World Health Organization; 2020. https:/www.who.int/news-room/fact-sheets/detail/nursing-and-midwifery.

2. "Decade of Action" Geneva: World Health Organization. Accessed January 27, 2020. https://www.un.org/sustainabledevelopment/decade-of-action/.

3. "Guidelines on core components of infection prevention and control programmes at the national and acute health care facility level". Geneva: World Health Organization; 2016. https://www.who.int/gpsc/ipccomponents-guidelines/en/.

\section{Publisher's Note}

Springer Nature remains neutral with regard to jurisdictional claims in published maps and institutional affiliations.

\section{Ready to submit your research? Choose BMC and benefit from:}

- fast, convenient online submission

- thorough peer review by experienced researchers in your field

- rapid publication on acceptance

- support for research data, including large and complex data types

- gold Open Access which fosters wider collaboration and increased citations

- maximum visibility for your research: over 100M website views per year

At BMC, research is always in progress.

Learn more biomedcentral.com/submissions 